\title{
Investigating the feasibility of text message reminders to improve adherence to nebulized medication in children and adolescents with cystic fibrosis
}

This article was published in the following Dove Press journal:

Patient Preference and Adherence

8 May 2017

Number of times this article has been viewed

\author{
Robert W Morton ${ }^{1,2}$ \\ Heather E Elphick ${ }^{2}$ \\ Elaine Edwards' \\ William J Daw ${ }^{1,2}$ \\ Noreen S West' \\ 'Cystic Fibrosis Unit, Sheffield \\ Children's Hospital, ${ }^{2}$ Academic Unit of \\ Child Health, University of Sheffield, \\ Sheffield, UK
}

Correspondence: Robert W Morton Cystic Fibrosis Unit, Sheffield Children's Hospital, Western Bank, Sheffield SIO 2TH, UK

Tel +44796878 8032

Email rwmorton99@gmail.com
Background: Children with cystic fibrosis (CF) often have suboptimal adherence rates to nebulized medication. Adherence barriers cited include forgetting to take the nebulizers, due to busy home and social lives. Text message reminders have been shown to be effective at improving adherence rates in other chronic diseases such as asthma and diabetes.

Objective: The objective of this study was to assess the feasibility and efficacy of sending text reminders for a prolonged period of time to children with $\mathrm{CF}$.

Materials and methods: Children with CF aged 5-16 years taking at least one medication via a nebulizer with an electronic adherence monitor were consented for the study. Text message reminders were sent to participants and/or parents via the hospital's automated text service, up to twice a day, for 6 months. The adherence rates for the 6-month text period were compared to the previous 6 months before the study. Rates were calculated for weekdays, weekends, and school holidays. Results: Seventeen participants were recruited to the study, with a mean age of 12 years and a mean forced expiratory volume in 1 second (FEV1) of $81 \%$ predicted. Fifteen children completed the 6-month text period, and I-neb data were accurately analyzed for 13 participants. The mean adherence rate in the 6 months receiving texts was $80 \%$, compared to $81 \%$ in the prior 6 months. Overall adherence rates on weekdays, weekends, and school holidays were equivalent during the 2 time periods. A subgroup of patients with moderate baseline adherence showed increased adherence during the text period, particularly at weekends.

Conclusion: It is feasible to send text message reminders to children with $\mathrm{CF}$, and they are amenable to this approach. Although text reminders do not increase rates in patients with existing optimal adherence, they may be of value in patients with more moderate baseline rates.

Keywords: cystic fibrosis, adherence, telehealth

\section{Introduction}

Nebulized medication is an integral part of treatment for many children and young people with cystic fibrosis (CF), but due to a high treatment burden, adherence rates to nebulized therapy are often suboptimal. ${ }^{1}$ Patients with low adherence rates to nebulized medication have been shown to have more pulmonary exacerbations requiring a course of intravenous antibiotics. ${ }^{2}$ This increased morbidity has been shown to increase health care utilization and associated cost. ${ }^{3}$

Adherence to nebulized medication is difficult to accurately measure, as subjective measures such as asking the patient and self-filled questionnaires have been shown to overestimate rates due to the social desirability bias. ${ }^{1}$ Prescription refill data are more objective, but they have also been shown to overestimate rates, as there is no guarantee that dispensed medication is actually taken. ${ }^{1}$ 
The development of Adaptive Aerosol Delivery (AAD) devices has enabled adherence rates to be electronically monitored, with the exact date and time of all doses logged. The I-neb (Philips Respironics, Guildford, UK) uses this technology to enable electronic adherence data to be downloaded and reviewed with patients in clinic, which is now becoming standard practice in the UK. ${ }^{4}$ Using this method, rates of adherence to nebulized therapy in children with $\mathrm{CF}$ have been recorded at around $65 \% .5,6$

Doubts about the need or effect of regular medication, concerns about the burden of medication for children with $\mathrm{CF}$, and oppositional behavior (defiant and disruptive behavior toward parents/carers) are classified as intentional adherence barriers. ${ }^{7}$ These barriers may be identified and addressed by having open discussions about electronically monitored adherence rates. ${ }^{4}$ If a child intends to take their nebulizers, they may face other practical, non-intentional barriers. When asked about these, children and adolescents report forgetting to take nebulizers due to busy home and social lives, and poor time management. ${ }^{8}$ Adherence to nebulized therapy has been shown to be significantly lower at weekends and school holidays, potentially indicating doses are forgotten in the absence of the weekday routine. ${ }^{6}$ Suboptimal adherence is likely to result as a combination of both intentional and non-intentional factors and, therefore, both must be reviewed and addressed in order to maintain increased rates. ${ }^{9}$

Text messages are a cheap and simple way of reminding people to take medication and have been shown to be effective at increasing adherence rates to medication in other chronic diseases such as asthma, ${ }^{10}$ diabetes, ${ }^{11}$ and HIV. ${ }^{12}$ In the UK, $48 \%$ of children aged 8-11 and 87\% aged 12-15 own a mobile phone. ${ }^{13}$ An American study has shown that children with $\mathrm{CF}$ as young as 7 are amenable and able to receive text message medication reminders. ${ }^{14}$

\section{Objectives}

The objective of this study was to investigate whether regular text message reminders sent from existing hospital automated systems can improve adherence to nebulized therapy in children with CF. We hypothesized that regular messages would increase adherence rates for children who previously forgot doses of nebulized medication.

\section{Materials and methods}

"Nebtext" was a historically controlled feasibility study carried out on children with CF in South Yorkshire, UK. Data from the intervention period were compared to that of the same participants in the 6 months prior to recruitment.
Children were eligible to participate if they had a diagnosis of $\mathrm{CF}$ with a positive sweat test and were aged between 5 and 16 years. They had to be taking at least one medication via the "I-neb" (Philips Respironics) for at least 6 months prior to the start of the study. Children were excluded if they or their parents did not have a mobile phone or could not speak English.

Consecutive potential participants were assessed for eligibility and approached in CF clinics at Sheffield Children's Hospital between October and December 2014. Written consent was taken from parents/carers and assent taken from the children themselves. Ethical approval for the study was granted by the National Research Ethics Service (NRES) committee South West - Exeter, in October 2014 (Research Ethics Committee [REC] reference 14/SW/1130).

\section{Intervention}

Prior to the study, questionnaires were handed out to all children attending the CF clinic in Sheffield, asking them which text messages they would like to receive from a list of options. The text with the most votes was chosen as the reminder text for the study (Figure S1).

After taking consent, the mobile phone number of the child and parent was recorded for children less than 12 years of age. If the child was 12 years or older, just the child's number was recorded.

All nebulized medications were recorded, and the times these medications were taken were discussed with the participants and parents/carers. At these specified times (computer program allowed a maximum of twice daily), for 6 months text message reminders were sent to the mobile phone of the child and/or parent/carer. Text messages were sent from the Sheffield Children's Hospital automated text reminder service, which is normally used to remind patients about upcoming clinic appointments. A specialized program was written by the information technology (IT) department at Sheffield Children's Hospital to manipulate this text service to send reminder text messages for the study. The texts for this study incurred no added cost from the established automated service. To increase convenience for participants, the times of reminder texts could be different for weekdays and weekends, and times were changed if required during the school holidays.

Participants received their usual care in the CF clinic, including regular reviews of I-neb adherence data, which is standard practice at Sheffield Children's Hospital.

\section{Outcomes}

The primary outcome was the difference in electronically recorded adherence rate (recoded by the I-neb) between 
the 6-month study period and the 6-month period prior to recruitment. Adherence was defined as percent of prescribed doses actually taken. All data were manually analyzed by counting the doses taken per day compared to number prescribed using the text file produced by the I-neb.

Secondary outcomes were difference in weekend adherence rates, difference in the number of days where no nebulized medication was taken at all, and difference in the total number of missed doses. Adherence rates were calculated for school holidays (August in the pretext period and the Christmas holidays for the text period). Any change in adherence of at least $5 \%$ between the time periods was documented for each participant. Participants' opinions on receiving text message reminders and their perceived utility were recorded at the end of the study via a questionnaire distributed in clinic.

\section{Statistical analysis}

As this was a feasibility study, there was no power calculation and statistical testing was minimized, in line with recommendations. ${ }^{15}$ Mean and median adherence rates were calculated and means compared using a paired Student's $t$-test.

\section{Changes to methods}

Initially data from the I-nebs was also uploaded and analyzed on the website www.pspnet.com, as it was in the standard clinic reviews at Sheffield Children's Hospital. However, during the period of results analysis, the www.pspnet. com website was discontinued by Philips, to be replaced with a new "Insight" online system. Therefore, all data were only analyzed using manual technique.

\section{Results}

There were 28 participants in the text message preference questionnaire, with "It's neb o'clock :)" receiving $43 \%$ of votes and "It's neb time :)" receiving 25\%. The full questionnaire results and text suggestions are available in (Figure S1).

In October 2014, there were 22 children taking at least one medication via the I-neb attending the CF clinic in Sheffield (Figure 1). These children were assessed for eligibility and 18 of these children who attended clinic in the recruitment period between October and December 2014 were approached and consented to take part in the trial. One participant declined to take part and, therefore, 17 participants were recruited to the trial. One participant withdrew after 21 days of the trial and one after 31 days, both citing the reason that their adherence was already satisfactory and they did not think texts would help. When the I-neb data were analyzed, two of the participants had incomplete data available. It transpired that these participants used additional inhalation devices (Podhaler; Novartis, Camberley, UK) for various periods of time and, therefore, accurate adherence rates could not be calculated.

The mean (range) age at baseline was 12 years (6-15) and the mean (range) forced expiratory volume 1 was $81 \%$ predicted (50-102). ${ }^{16}$ A total of $76 \%$ of participants at baseline were female. Table 1 shows the number of nebulized actuations the participants were taking at recruitment.

The overall mean (standard deviation [SD]) adherence during the text period was $80 \%$ (30), compared to the mean in the previous 6 months, which was $81 \%$ (25) (Table 2). There was no overall difference between the 6 month pretext control period and the 6 month text intervention period for the secondary outcomes (Table 3 ).

Of the 13 participants whose data were analyzed, when compared to the previous 6 months, the adherence increased by at least $5 \%$ in two participants, decreased in two, and was unchanged in nine (Figure 2).

At the conclusion of the study, only six of the 13 questionnaires were returned to clinical staff. Five (83\%) participants said they found it sometimes useful to receive text message reminders, with one finding them useful all the time. Two people (33\%) thought they were most useful on weekdays, two (33\%) on weekends, and two (33\%) during school holidays. All respondents thought texts were a good way to remind people to take their nebulizers, and five $(83 \%)$ said they did not mind being sent regular text message reminders.

\section{Discussion}

The results of this study show that it is feasible to send reminder text messages to children and adolescents with $\mathrm{CF}$ over a 6-month period. However, these text messages did not affect the overall adherence rates to nebulized medication in our study group.

This study had good generalizability, as the participants were children with CF taking common nebulized medications. Automated text services are widely used in hospitals in developed countries, and we have shown they can be effectively programmed to send regular free reminder text messages to patients.

The results show that the children and adolescents in the Sheffield clinic had a high mean pretext adherence of $81 \%$, which was maintained but not increased during the text period $(80 \%)$. The high baseline adherence rates were also maintained during weekends and school holidays, with no increase in these rates during the text period. This high baseline adherence is a credit to the participants in the trial 


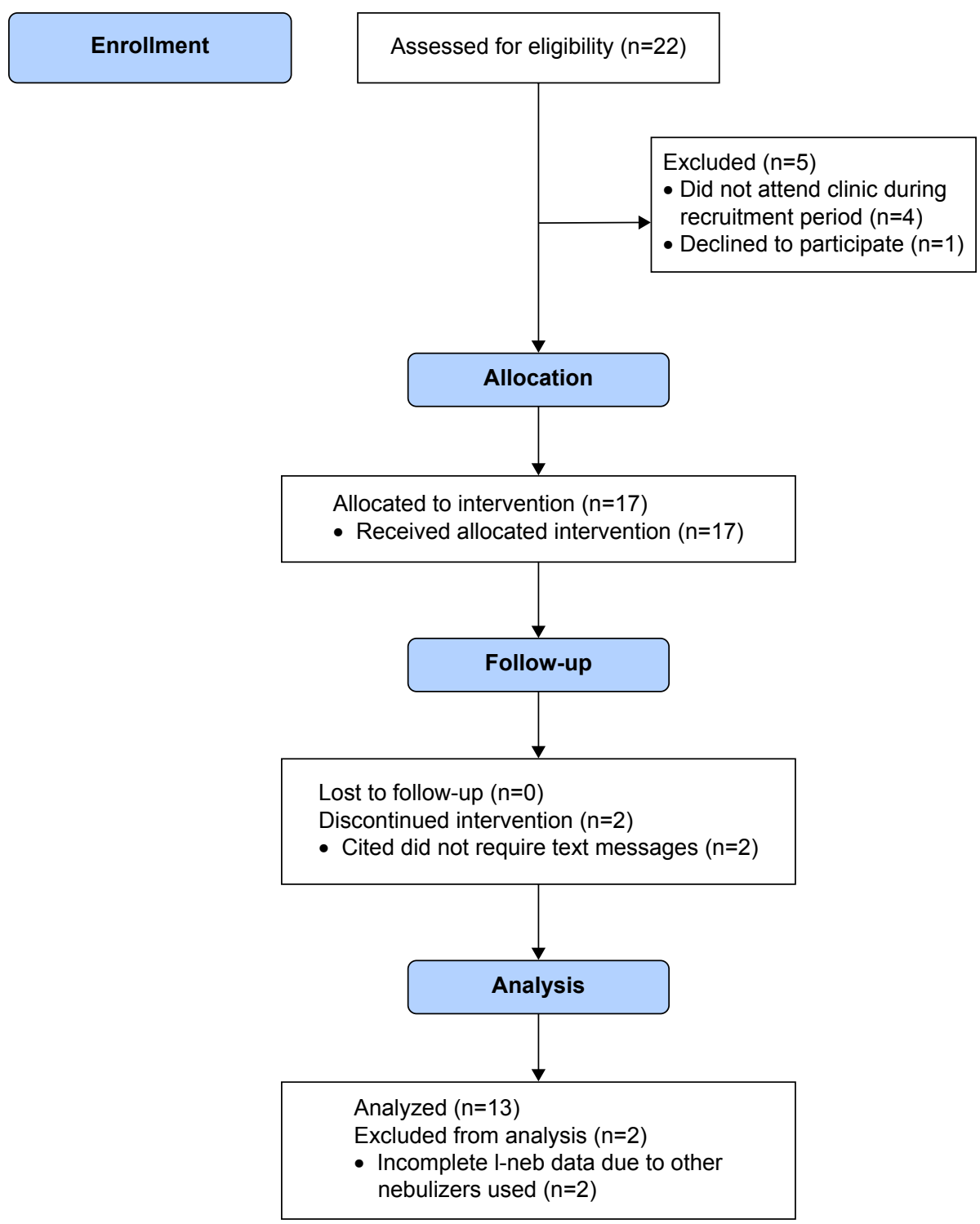

Figure I Flow chart showing progress of participants through the study.

Table I Total number of nebulized actuations taken by the 13 participants who completed the study

\begin{tabular}{|c|c|c|}
\hline $\begin{array}{l}\text { Total number of nebulizer } \\
\text { actuations per day }\end{array}$ & $\begin{array}{l}\text { Number of } \\
\text { participants (\%) }\end{array}$ & Medications taken \\
\hline I & $5(38)$ & DNase od \\
\hline 2 & I (8) & Promixin bd \\
\hline \multirow[t]{2}{*}{3} & $2(15)$ & DNase od \\
\hline & & Promixin od \\
\hline \multirow[t]{5}{*}{4} & $2(15)$ & Bramitob bd \\
\hline & & ( 2 actuations bd) \\
\hline & $2(15)$ & DNase od \\
\hline & & Promixin bd \\
\hline & & Hypertonic Saline od \\
\hline \multirow[t]{3}{*}{5} & I (8) & Bramitob bd \\
\hline & & ( 2 actuations bd) \\
\hline & & DNase od \\
\hline Total & 13 & \\
\hline
\end{tabular}

Note: od = once daily, bd = twice daily. and is likely the result of the established regular adherence reviews and dialogue in clinic facilitated by the advent of the I-neb technology.

Despite a small sample size, closer analysis of the participants' adherence potentially reveals three distinct subgroups (Figure $2 \mathrm{~A}-\mathrm{C}$ ). In the group with the highest

Table 2 Mean (standard deviation, SD) and median (interquartile range, IQR) adherence rates for the 6-month text period and previous 6 months

\begin{tabular}{lll}
\hline Time period & Mean (SD) & Median (IQR) \\
\hline Pretext period & $80.6(25.0)$ & $95.2(68-98)$ \\
Text period & $80.2(29.5)$ & $94.8(76-98)$ \\
P-value & 0.9 & \\
\hline
\end{tabular}


Table 3 Secondary outcomes for the pretext and text periods

\begin{tabular}{|c|c|c|c|c|c|c|c|c|}
\hline Time period & $\begin{array}{l}\text { Mean (SD) } \\
\text { weekday } \\
\text { adherence }\end{array}$ & $\begin{array}{l}\text { Median (IQR) } \\
\text { weekday } \\
\text { adherence }\end{array}$ & $\begin{array}{l}\text { Mean (SD) } \\
\text { weekend } \\
\text { adherence }\end{array}$ & $\begin{array}{l}\text { Median (IQR) } \\
\text { weekend } \\
\text { adherence }\end{array}$ & $\begin{array}{l}\text { Mean (SD) } \\
\text { school holiday } \\
\text { adherence }\end{array}$ & $\begin{array}{l}\text { Median (IQR) } \\
\text { school holiday } \\
\text { adherence }\end{array}$ & $\begin{array}{l}\text { Mean (SD) } \\
\text { missed } \\
\text { doses }\end{array}$ & $\begin{array}{l}\text { Mean (SD) } \\
\text { missed } \\
\text { days }\end{array}$ \\
\hline Pretext period & 79.5 (25.7) & $94.1(73-96)$ & $79.5(25.8)$ & 95.4 (64-98) & $80.6(27.6)$ & 93.5 (73-97) & $75.9(104.0)$ & $20.2(38.2)$ \\
\hline Text period & $78.5(29.8)$ & 91.5 (77-98) & $80.5(30.6)$ & 95.2 (82-98) & $77.4(32.8)$ & $92.5(8 I-95)$ & $58.1(7 \mid .4)$ & $26.2(51.0)$ \\
\hline$P$-value & 1.0 & & 1.0 & & 0.43 & & 0.42 & 0.21 \\
\hline
\end{tabular}

Note: Adherence rates are in percentages.

Abbreviations: SD, standard deviation; IQR, interquartile range.

pretext adherence rates (group A, eight participants $>90 \%$ ), there was no increase or decrease in adherence $>5 \%$. This indicates that the majority of participants in this study already had excellent systems in place for remembering to take their nebulizers, helped by clinic adherence reviews. In these participants, text message reminders were unnecessary and ineffective as adherence rates were already optimal. The systems were also effective at weekends and school holidays, rendering text message reminders at these times redundant. In the group of three participants with moderate pretext adherence (group B, three participants $60 \%-80 \%$ ), adherence improved $>5 \%$ in two of these during the text period, not changing in the third. This could indicate that in this group with moderate adherence, rates can be improved by regular text messages prompting them to take nebulizers on the few occasions they would have otherwise forgotten. In this group, the rates of all the three increased by at least $5 \%$ at the weekends and school holidays, indicating that the messages were useful in the absence of usual weekday routines. In the group with the lowest pretext adherence rates (group C, two participants $<50 \%$ ), the rates fell further during the text period. This may indicate that in this group of patients there is no effective system or routine in place to facilitate regular intake of medication and, therefore, any prompts such as text messages are futile. The messages may have been unpopular, and the daily reminders may have potentially exacerbated oppositional behavior and caused adherence rates to fall further. Alternatively, forgetting doses was not an adherence barrier for this group and, therefore, the reminder texts had no effect, or they cited forgetting as a barrier when actually they had negative medication beliefs. It has been shown in adults that people with negative medication beliefs are also more likely to forget doses and, therefore, text message interventions are futile if they do not also address the negative beliefs. ${ }^{17}$

The adherence rates in this study differed from those published elsewhere. McNamara et al in 2009 reported that the mean adherence rate for their population in Liverpool, UK, was $67 \% .^{5}$ This figure was supported by Ball et al in 2013 , recording a mean rate of $65 \%$ in Liverpool and Leeds. ${ }^{6}$ Both of these studies reviewed adherence data retrospectively, analyzing all I-neb data from participants attending

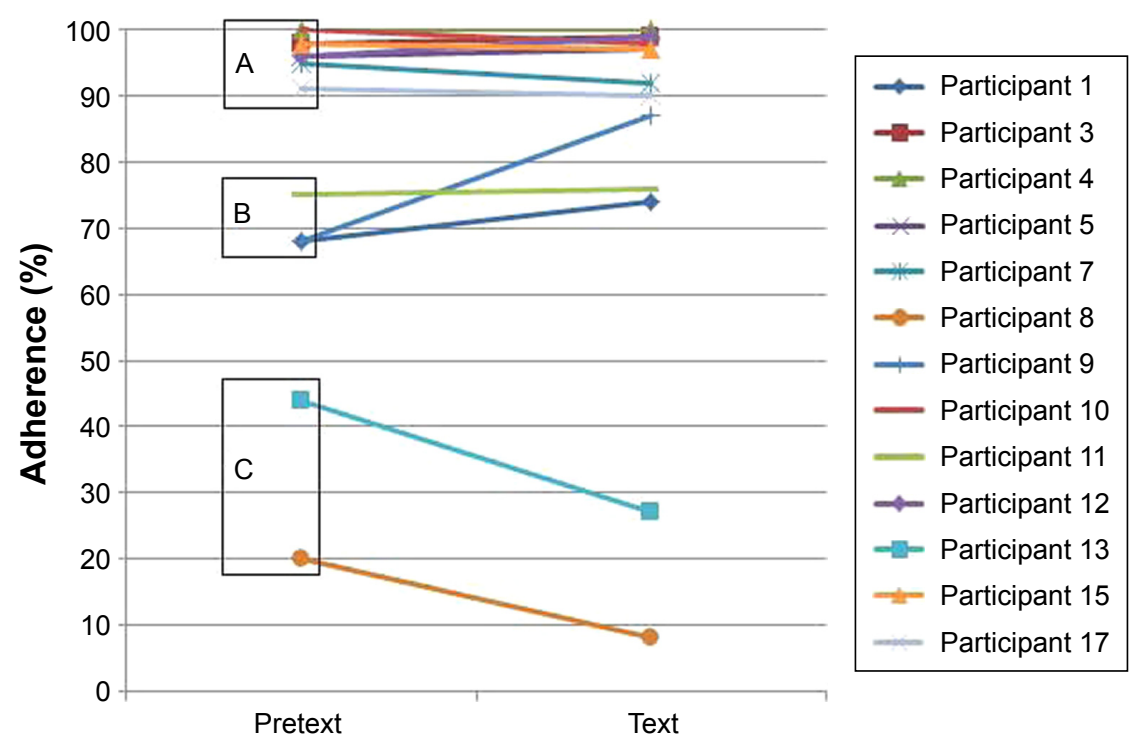

Figure 2 Adherence rate for individual participants in the 2 time periods.

Notes: Sub-group $A=$ good baseline adherence $(\geq 80 \%), B=$ moderate baseline adherence $(50-79 \%), C=$ poor baseline adherence $(<50 \%)$. 
clinics in their centers. With this approach, data from all participants, and not just the most adherent, can be analyzed. In our study, the prospective nature and the necessity of informed consent meant that the least adherent patients could not attend clinic during the advertised recruitment period, refuse consent, or withdraw from the study, leaving only the more adherent participants in the study. Ball et $\mathrm{al}^{6}$ showed that adherence rates were significantly lower at weekends and school holidays. Overall, we did not see this trend, with equivalent adherence rates on weekdays, weekends, and school holidays. However, when our data were reviewed for the three participants with similarly moderate adherence to those in the Ball study $(60 \%-80 \%)$, the adherence rates were lower at weekends in two of these, and the weekend and holiday rates increased in all the three during the text period. This could suggest that the text messages are of use to these patients with moderate adherence who forget to take their nebulizers at the weekends in the absence of a normal routine. Accounting for the potentially falsely elevated adherence rates in our study due to selection bias, we could assume our population is similar to those in Liverpool and Leeds, with a more moderate true mean adherence rate. We would, therefore, potentially have seen a greater effect of the texts if we had included all patients in our study and analyzed data retrospectively, as part of a service evaluation. Ethical approval was not granted for this approach in this study, but with the positive patient feedback reported here and the potential to improve moderate adherence, this approach could be considered in future studies.

This study used all the participants available in our CF center attending clinic during the recruitment period, but the numbers were too small to carry out a randomized controlled trial (RCT). Therefore, all participants received text messages, comparing adherence data to a retrospective control period. Other confounding factors may have influenced adherence outcomes in the two different time periods, including seasons, participant maturity, and changing home or school circumstances. By comparing data to the 6 months immediately previous, any changes over time were minimized. The holiday periods in the two time periods were different as one was summer and one Christmas. This was unavoidable in the 6-month comparative periods and common features of holiday behavior would have been present in both. Although text messages were sent regularly at preset times, there was no guarantee that children were at home and available to take their nebulizers when they received the messages.

Of the 13 questionnaires handed out in clinic after the study was completed, only six were returned. This may be because the participants simply forgot to return the questionnaire. If their feedback was negative however, they may have preferred not to report this, for fear of offending the research or clinical staff upon whom their on-going care is reliant. This would potentially bias the results, as only positive feedback would be recorded.

The majority of participants in this study had preexisting adherence rates greater than $80 \%$. There was, therefore, a ceiling effect seen, with minimal capacity for further improvement. The text messages we sent were the same every day, and there was likely to have been a degree of habituation to the automated messages, reducing their daily impact. The majority of participants who returned questionnaires thought the texts were useful some of the time, rather than all of the time. Any potential impact of reminder text messages is likely to be short term, as patients get used to the same regular messages and start to ignore them. They may, therefore, have the most value at selected short periods of time when adherence is most important, for example during pseudomonas eradication regimens or during school holidays.

Habituation and reminder fatigue be also overcome by changing the texts received, or by only sending reminder messages if the nebulizer had not been actuated. This approach has been shown to improve adherence to inhaled medication in asthma using a Real Time Medication Monitoring system. ${ }^{18}$

During the course of this study, it became apparent that the clinic review of downloaded I-neb data was often a difficult and potentially inaccurate process. The www.pspnet.com website was of limited value when patients were on multiple medications via their I-neb, as there was no way of determining which specific medications were taken. In addition, I-neb adherence reviews could only be performed if the patient brought their I-neb with them to clinic. It is likely the most adherent patients brought their nebulizer regularly, happy to review the positive data, whereas the least adherent patients often "forgot" their I-neb to avoid being looked upon unfavorably by the medical team. It is these least adherent patients who would benefit most from an open and structured dialogue about the adherence barriers they face, but without any data to review and discuss, health professionals are powerless to intervene.

The newer "Insight" system introduced by Philips tries to counter the problem of patients not bringing their nebulizers to clinic by enabling the devices to be docked at home and uploaded via the internet. Unfortunately this system still requires the patient to remember to dock the device, something which can also be forgotten. The future for 
electronic monitoring for nebulized medications in CF would be a system where the data would be automatically uploaded remotely via wireless internet, not requiring any patient involvement. All patients' data could then be reviewed, and the least adherent patients could be identified and helped. The nebulizers themselves would have a way of identifying which medication was taken, and adherence reviews could then be based on more accurate data. Before implementing this approach, opinions should be sought, and consent from patients would have to be obtained. The "big brother" approach may be unpopular with some and potentially may lead to patients disengaging with the medical profession. This was possibly seen by the small number of participants returning their questionnaires in this study, potentially concealing negative views. An unpopular approach may lead to an increase in oppositional behavior, and falling adherence, as was potentially seen in the two participants in this study with the lowest adherence.

Based on the results of our study, we would recommend a larger multi-center RCT to further explore the benefits and applicability of this technology in children and adolescents with $\mathrm{CF}$. Inclusion criteria could state existing poor to moderate adherence rates $(<80 \%)$, to focus on the patients most likely to benefit from the intervention. During the study, regular adherence reviews would enable any participants with falling adherence to be identified and helped. If it was apparent that the text messages were unpopular or increasing negative oppositional behavior, they could be discontinued. Illness perceptions and medication beliefs should be identified before the study, and those with negative beliefs could be targeted with separate messages to address these views.

\section{Conclusion}

In a group of children and adolescents with good baseline adherence, overall rates were not improved by sending regular reminder text messages. However, in patients with moderate adherence, there is potential for text messages to increase adherence rates, particularly at weekends and school holidays. We have shown it is feasible to send regular text reminders via established automated systems, and the young people in our study were generally amenable to this approach.

\section{Acknowledgments}

We would like to thank the nursing staff in the Sheffield Children's Hospital CF unit for their help facilitating this study in clinic. We would like to thank Richard Jackson in the IT department at Sheffield Children's Hospital for writing the computer program to send reminder messages and facilitating their use throughout the text period. We would like to thank Rosemary Ball at Leeds General Infirmary for her help and advice with the study and in the preparation of the manuscript. There was no funding required for this study, and the work was carried out by the authors without charge, or for RWM and WJD, as part of a higher degree. The text message intervention incurred no financial cost.

\section{Author contributions}

RWM devised the idea for the study, gained ethical approval, consented and recruited participants, collected results, and wrote the manuscript. HEE and NSW supervised the setup and application of the study and helped write and edit the manuscript. EE helped to set up the study, facilitated the intervention and collection of results, and reviewed the manuscript. WJD recruited the participants of the study, facilitated the collection of results, and helped write and edit the manuscript. All authors contributed toward data analysis, drafting and revising the paper and agree to be accountable for all aspects of the work.

\section{Disclosure}

The authors report no conflicts of interest in this work.

\section{References}

1. Modi AC, Lim CS, Yu N, Geller D, Wagner MH, Quittner AL. A multimethod assessment of treatment adherence for children with cystic fibrosis. J Cyst Fibros. 2006;5(3):177-185.

2. Eakin MN, Bilderback A, Boyle MP, Mogayzel PJ, Riekert KA. Longitudinal association between medication adherence and lung health in people with cystic fibrosis. J Cyst Fibros. 2011;10(4):258-264.

3. Quittner AL, Zhang J, Marynchenko M, et al. Pulmonary medication adherence and health-care use in cystic fibrosis. Chest. 2014;146(1): $142-151$

4. McCormack P, Southern KW, McNamara PS. New nebulizer technology to monitor adherence and nebulizer performance in cystic fibrosis. J Aerosol Med Pulm Drug Deliv. 2012;25(6):307-309.

5. McNamara PS, McCormack P, McDonald AJ, Heaf L, Southern KW. Open adherence monitoring using routine data download from an adaptive aerosol delivery nebuliser in children with cystic fibrosis. $J$ Cyst Fibros. 2009;8(4):258-263.

6. Ball R, Southern KW, McCormack P, Duff AJ, Brownlee KG, McNamara PS. Adherence to nebulised therapies in adolescents with cystic fibrosis is best on week-days during school term-time. J Cyst Fibros. 2013;12(5):440-444.

7. Modi AC, Quittner AL. Barriers to treatment adherence for children with cystic fibrosis and asthma: what gets in the way? J Pediatr Psychol. 2006;31(8):846-858.

8. Bregnballe V, Schiotz PO, Boisen KA, Pressler T, Thastum M. Barriers to adherence in adolescents and young adults with cystic fibrosis: a questionnaire study in young patients and their parents. Patient Prefer Adherence. 2011;5:507-515.

9. Wildman MJ, Hoo ZH. Moving cystic fibrosis care from rescue to prevention by embedding adherence measurement in routine care. Paediatr Respir Rev. 2014;15 (Suppl 1):16-18. 
10. Tran N, Coffman JM, Sumino K, Cabana MD. Patient reminder systems and asthma medication adherence: a systematic review. J Asthma. 2014;51(5):536-543.

11. Vervloet M, van Dijk L, Santen-Reestman J, et al. SMS reminders improve adherence to oral medication in type 2 diabetes patients who are real time electronically monitored. Int J Med Inform. 2012; 81(9):594-604.

12. Mbuagbaw L, van der Kop ML, Lester RT, et al. Mobile phone text messages for improving adherence to antiretroviral therapy (ART): an individual patient data meta-analysis of randomised trials. BMJ Open. 2013;3(12):e003950.

13. Ofcom. Children and parents: media use and attitudes report. Available from: https://www.ofcom.org.uk/_data/assets/pdf_file/0027/76266/ childrens_2014_report.pdf. Accessed December 13, 2016.

14. Johnson KB, Culpepper D, Scott P, Gordon JS, Harris C. The utility of providing automated medication dose reminders to young children on chronic medication. J Telemed Telecare. 2011;17(7):387-391.
15. Lancaster GA, Dodd S, Williamson PR. Design and analysis of pilot studies: recommendations for good practice. J Eval Clin Pract. 2004;10(2):307-312.

16. Quanjer PH, Stanojevic S, Cole TJ, et al; ERS Global Lung Function Initiative. Multi-ethnic reference values for spirometry for the 3-95-yr age range: the global lung function 2012 equations. Eur Respir J. 2012; 40(6):1324-1343.

17. Unni EJ, Farris KB. Unintentional non-adherence and belief in medicines in older adults. Patient Educ Couns. 2011;83(2):265-268.

18. Vasbinder EC, Goossens LM, Rutten-van Molken MP, et al. e-Monitoring of Asthma Therapy to Improve Compliance in children (e-MATIC): a randomised controlled trial. Eur Respir J. 2016;48(3):758-767. 


\section{Supplementary material}

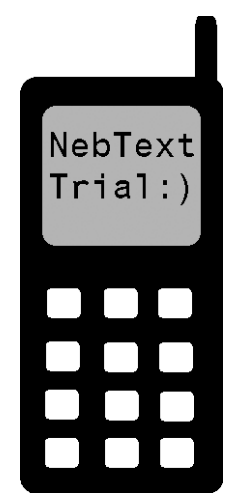

We are going to carry out a trial at Sheffield Children's Hospital to see whether people remember to take their nebulizers more if we text to remind them.

If we were to text you twice a day to remind you to take your nebulizer, which of the following texts would you like to receive?

Please tick the text or texts you think are best: Total 28 responses

Please remember to take your nebulizer :) $\quad \square \quad 1$

Don't forget your neb :) $\quad \square \quad 4$

It's time for your neb :) $\quad \square \quad 4$

Dr West says it's time for your neb :) $\quad \square \quad 5$

Elaine says it's time for your neb :) $\quad \square \quad 3$

It's neb time! :) $\quad \square \quad 7$

It's neb'o'clock! :) $\quad \square \quad 12$

None of the above $\quad \square \quad 4$

Other text suggestion

Thank you for your suggestions; please put this form in the box on the reception desk.

Figure SI Text suggestions form and results.

Patient Preference and Adherence

\section{Publish your work in this journal}

Patient Preference and Adherence is an international, peer-reviewed, open access journal that focuses on the growing importance of patient preference and adherence throughout the therapeutic continuum. Patient satisfaction, acceptability, quality of life, compliance, persistence and their role in developing new therapeutic modalities and compounds to optimize clinical outcomes for existing disease states are major areas of interest for the journal. This journal has been accepted for indexing on PubMed Central. The manuscript management system is completely online and includes a very quick and fair peer-review system, which is all easy to use. Visit http://www. dovepress.com/testimonials.php to read real quotes from published authors.

\footnotetext{
Submit your manuscript here: http://www.dovepress.com/patient-preference-and-adherence-journal
} 